\title{
Design and Culture in the Making of Happiness
}

\author{
Maria Luísa Costa and Gonçalo Estêvão
}

\begin{abstract}
Design responds to the needs of individuals, being happiness and wellbeing the subject of an increasing number of studies, which gave rise to a new discipline, Positive Psychology. From these new approaches and concerns related to subjective well-being comes Positive Design, whose objective is to promote the well-being of individuals and communities in connection with a culture of innovation. The cultural routes made accessible through wayfinding systems, make it possible to put Heritage in dialogue, emphasize the culture, memory and history of communities, providing citizens with meaningful experiences that will have an impact both in the short and long run, thus becoming agents for the happiness of individuals. This article discusses the concept of Positive Design based on Positive Psychology, analyzes the evolution and importance of Heritage in the Culture of peoples and communities, questioning how the Wayfinding Systems developed for cultural promotion can integrate the practice of Positive Design and how this contributes to the subjective well-being of individuals.
\end{abstract}

Keywords Positive design $\cdot$ Heritage $\cdot$ Cultural routes $\cdot$ Wayfinding

\section{Introduction}

Design as a holistic discipline responds to social and cultural needs, assuming itself as a catalyst for a changing society. The designers' view of their professional practice and their social responsibility adjusts to social changes and trends. It is a fact which

\footnotetext{
M. L. Costa ( $\varangle)$

Centro de Investigação em Arquitetura, Urbanismo e Design, Universidade de Lisboa, Rua Sá Nogueira, Pólo Universitário, Alto da Ajuda, 1349-063 Lisbon, Portugal e-mail: design.luisacosta@gmail.com

Instituto Superior Miguel Torga, Largo da Cruz de Celas nº 1, 3000-132 Coimbra, Portugal

G. Estêvão

Faculdade de Psicologia da Universidade de Lisboa, Alameda da Universidade, 1649-013 Lisbon, Portugal
} 
research in the area of design has been promoting exponentially, through the identification of needs and the application of practices, more aware and in line with the well-being of populations and communities, thus generating responses and actions differentiated in order to safeguard a better world, socially more just and culturally more participatory, we would say, eventually, happier.

The idea of happiness takes on enormous importance in contemporary society, as demonstrated by several studies in the field of Psychology, as well as by the emergence of a new area of study within Psychology, called Positive Psychology, which is reflected in the scope of design thinking and practice, and from which Positive Design results.

The Delft Institute of Positive Design (DIOPD), founded in 2011, has the mission of creating knowledge that allows designers to formulate strategies which contribute to people's happiness, not only in terms of usability, that is, of the users' relationship with products, but also in the construction of a healthier society and a better world, since it has been verified that material wealth (access to multiple consumer goods) does not seem to translate into happiness. It is, therefore, the objective of Positive Design to create opportunities to improve the life and well-being of individuals and populations, instead of just trying to eliminate their problems (https://diopd.org).

Culture, properly communicated and promoted by design, can contribute to the well-being of populations, since culture is a human construction, resulting from the history, memories and ways of doing of different individuals, communities, societies and civilizations, manifesting on their tangible or intangible heritage.

The concept of Heritage has evolved significantly. The 1st International Conference for the Conservation of Historical Monuments, in 1931, which resulted in the Charter of Athens (1931), assumes itself as a historical landmark in this evolution, since the notion of Heritage is no longer exclusively linked to family structures and institutions, promoting the concept of Historical Heritage, intended for the collective enjoyment of the community. Many recommendations and conventions follow, extending the concept of heritage and emphasizing the importance of its enjoyment within communities. Currently, the need to preserve Intangible Cultural Heritage is emphasized through a communication that promotes cultural diversity in a globalized world.

The communication and promotion of the different types of heritage can be put into dialogue through cultural routes, communicated through wayfinding systems which, more than facilitating the access between a certain point and another one wishes to reach, must enable significant activities both cognitive as playful, rooted in cultural values providing the experience and involvement of individuals.

\section{Design and Happiness}

As can be seen in Fig. 1, in the last two decades there has been a huge growth in research on happiness and subjective well-being (Myers and Diener 2018), a fact that reflects the emergence of a new discipline in psychology: Positive Psychology. 


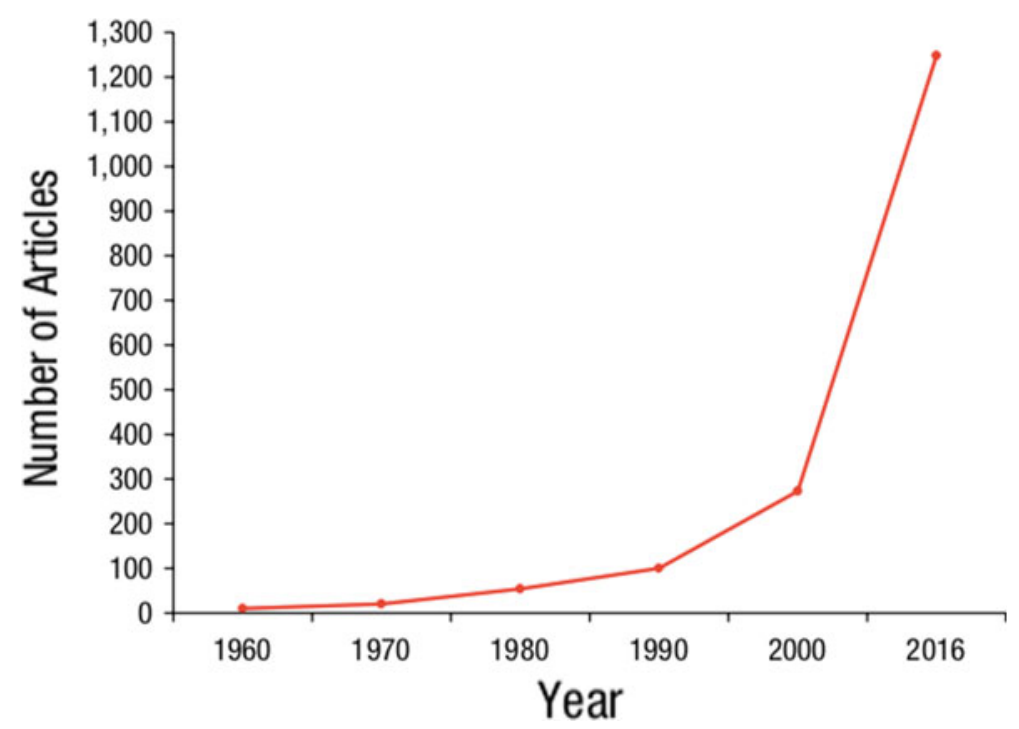

Fig. 1 Number of articles about happiness, per year (Myers and Diener 2018)

Maslow introduced the term Positive Psychology in 1954, but Seligman and Csikszentmihalyi popularized it in 2000 (Seligman and Csikszentmihalyi 2000), in a special edition of the American Psychologist magazine. The published article reflects a paradigm shift, since psychology has always focused more on the negative part of the human psyche and on how to deal with human unhappiness and adversity than on issues related to well-being and happiness.

However, due to the expansion of research in this scientific field, positive psychology will start to encourage studies on happiness, in order to understand what makes people happy and flourish (Seligman and Csikszentmihalyi 2000).

In summary, we can say that happiness is a multifaceted concept that not only includes more positive and less negative emotions, but also contains a cognitive component relating to life satisfaction (Diener and Biswas-Diener 2008). "Happiness, then, allows for a small dose of negative feelings while we are frequently experiencing positive ones. The balance, however, should heavily tilt in favor of the pleasant emotions. There is also a "cognitive," or thinking, component to well-being" (Diener and Biswas-Diener 2008).

Happiness is more than simply an emotion; it is a broad psychological state of which emotions are only a part.

In a study carried out in 2010, Schueller and Seligman (2010) argue that pleasure, involvement and meaning consist of the three elements capable of providing wellbeing and that the three combined aspects will provide a happier life for individuals. However, these authors argue that, when considering these three elements, meaning and involvement have a greater influence on well-being than pleasure. 
Seligman (2011) refers that well-being is a construct, that has five measurable elements: positive emotions (of which happiness and life satisfaction are all aspects); engagement, relationships, meaning and achievement, and states that none of these elements defines well-being, but each contributes to it.

\section{Positive Design}

Design is present in our daily lives and it depends on how we interact not only with objects, but also with information. This interaction, in turn, promotes emotional states. This perspective has led to investigation and the development of several theories on how the design process can be oriented towards happiness and subjective well-being. This was named by some authors as Positive Design.

Thus, we found that Positive Design derives from new approaches to positive psychology and the value attributed to subjective well-being.

According to the Delft Institute of Positive Design (https://diopd.org), Positive Design aims to promote the well-being of individuals and communities, and is deeply related to happiness and the commitment to develop a culture of innovation where technology can be a way of improving life, and not just a tool to solve problems.

Also, according to DIOPD (https://diopd.org), researchers have been working based on the knowledge of Positive Psychology to clarify the principles of positive emotions and well-being, in an attempt to answer what are the conditions for human flourishing; what are the determining factors for achieving well-being and what is its effect on behaviour and health; what is the role of different emotions in well-being and how can people increase their happiness.

In an attempt to create a tool to help those involved in product design and despite not using the positive design nomenclature, Jordan's approach (Jordan 2000) already follows in this direction, identifying four types of pleasure that products can bring. These are: physio-pleasure, socio-pleasure, psycho-pleasure and ideo-pleasure. The physical pleasure related to the pleasures of the body and coming from the senses. Socio-pleasure comes from the pleasure that derives from the relationship with others, which can be intentional or accidental, such as a coffee machine that ends up promoting conviviality around it. Psycho-pleasure has to do with the cognitive and emotional states that the products promote. The ideo-pleasure has to do with the individual's representation of objects or interaction and how this fits with their values.

For Desmet and Pohlmeyer (2013), Positive Design initiatives must deliberately intend to increase people's subjective well-being, resulting in an increased appreciation of their lives. This objective should be paramount.

These authors propose a framework for positive design composed of three components of subjective well-being: Design for Pleasure:-experience positive affect; Design for Personal Significance-pursuing personal goals and Design for Virtue-being a morally good person. 
Design for pleasure is related to the well-being in the moment, the subjective well-being that derives from the sum of positive and pleasurable moments. Here the focus is on the here and now, on promoting positive emotions and the absence of negative emotions (Desmet and Pohlmeyer 2013).

Design for Personal Significance, here the focus is no longer the moment, but the individual's goals and aspirations. Whether these are in the future, making them easier to reach, or in the past, helping to recall or recover already achieved aspirations. In virtue design, the focus is on behavior that the individual considers correct and appropriate. The design must be appropriate to the individual's values (Desmet and Pohlmeyer 2013).

Design for Virtue, is related to the virtuous behavior, it is based on a moral level.

It should be noted that this structure proposes that positive design goes beyond mere pleasure, because although pleasure or positive emotions are a fundamental component of subjective well-being, positive design must go beyond this. It will contain the three components, although each of them can serve individually as a guide for positive design (Desmet and Pohlmeyer 2013).

Thus, an experience-oriented design that contributes to subjective well-being generating pleasure will only be positive design if it also addresses the individual's sense of virtue and personal meaning (Desmet and Pohlmeyer 2013). However, the three components do not have to be addressed at the same level. There may be an emphasis on only one, as long as the other two are not compromised. Any type of design in a certain way will contribute to the subjective well-being of someone, even if it is by reducing threats to well-being, but only through the presence of these three components is it possible to design for human flourishing.

Desmet and Pohlmeyer (2013), also propose five characteristics that positive design should have: should be oriented towards possibilities; swing; adjusted to the individual; user involvement; and long-term impact.

The "orientation towards possibilities" has to do with changing the design orientation from problems to possibilities. Instead of trying to reduce or try to resolve negative circumstances, positive design should go beyond neutral and try to create new possibilities. For example, the absence of discomfort is different from comfort. A problem-oriented design will try to reduce or eliminate discomfort, while a possibility-oriented design will try to stimulate or add comfort.

The "balance" has to do with the degree to which the three components of positive design are used. They do not have to be addressed at the same level and positive design can choose to focus on one of them, as long as it does not cause displeasure, promotes immoral behavior or threatens to achieve personal goals.

The "adjusted to the individual" means that positive design must take into account that well-being is subjective, precisely because it is different for all people, and therefore must take care of important general aspects, such as relationships with others and the contribution to a greater good, but take into consideration for whom it is developed, what is the context, lifestyle or personal goals, in order to ensure adequacy.

"User involvement" is associated with the idea that design will only promote wellbeing if the individual gets involved in the process. The individual's flourishing is 
directly dependent on his involvement and interest. So, design should promote and facilitate well-being by promoting thoughts or behaviours, but in order to promote flourishing they will need to require user involvement.

In the "long-term impact" factor, positive design should have a long-term perspective, although the positive emotions component of subjective well-being is associated with immediate gratification. Life satisfaction is related to a longer assessment of well-being. And happiness is very much associated with a balance between these two perspectives. If positive design is to promote happiness and individual flowering, it should promote long-term effects. The characteristics listed above related to the practice of Positive Design have tangential points with Emotional Design, this depends on the interaction between user and product, and can motivate a set of positive experiences.

Norman (2004), refers to the importance of time, but as being the element that, in the final analysis, will verify if the object is relevant, that is, if it stands the test of time then it is relevant. Many objects elicit emotional activation due to the novelty, but the process of familiarization with the stimuli causes the repeated presentation to the same stimulus to stop provoking the emotional response with the same intensity. According to the author, one of the possibilities is complexity, that is, the ability of the stimulus to continue to present new opportunities to be explored, or the way it is learnt to never be complete.

However, it is considered that the initial emotional impact may be sufficient to keep it fresh and withstanding the test of time. This high initial impact will be present in the memory. In other words, it can stop causing the same emotional state but it still allows you to recover it through memory.

This Design, which is intended to be Positive, a Design for happiness and wellbeing, cannot continue to be directed towards consumption and commerce. Designers have a great influence on the lives of citizens, through the messages they produce and, according to Berman (2009), "we all have a duty to make sure that the inventions we embrace and enhance by design are not just clever but also wise; that we don't just create intriguing, marketable stuff, but that our creations are aligned with a sustainable future for human cultures and civilization as a whole." Appealing to consumption, the designers thus promise access to a better world, happiness and well-being, but in reality, they often promote sadness and frustration in the long run.

Design projects that provide knowledge and appreciation of intangible dimensions of our culture, when combined with collaborative practices, with the involvement of citizens and communities, can contribute to a society where subjective well-being and happiness are closer to being achieved.

\section{City, Culture and Heritage}

Our reading of the city is a construction which depends on the existing physical images, that is, its natural, landscaped and built space, but also on intangible images, 
which are rooted in a subjective dimension of those who "read" the city, images composed by experiences, memories, traditions and emotions (Costa 2013).

According to Lynch (1960), the greater the legibility of the city, the greater our comfort and well-being. This legibility contributes to its structural material elements, streets, corners, as well as sensory perception, its light, colour, scent, and the space of the city, in addition to being organized, must be poetic and symbolic, revealing to us its traditions, its history and memories.

This sensitive dimension of the city, consisting of experiences, memories, traditions and emotions is rooted in culture since, according to Saraiva (2003), culture is everything that does not depend on nature and is added to it by the spirit, and that includes utilitarian, playful, intellectual and affective activities.

According to Titiev (1969), the term culture is used by anthropologists to describe instruments that are not genetically acquired by man, as well as all the behavioural facets acquired by man after birth.

Thus, we maintain that all cultures have a pattern of behaviour, but this pattern is neither static nor pre-existing to a community. According to Cuche (2003), culture is always a process of construction, deconstruction and reconstruction.

Culture is a dynamic process, to which all groups of individuals contribute, as well as their social, scientific, technological and environmental practices. Some professional groups play a decisive role as catalysts for social and cultural changes, among which we highlight the designers, who create and promote experiences and who, according to Press and Cooper (2009), when creating experiences and meanings, also create culture and future.

The notion of culture is intrinsically linked to the notion of heritage, both in its material and immaterial dimensions, integrating the beliefs, ideas and values, intangible dimensions that constitute the material of culture, as well as the tangible ones such as: objects, symbols and technology that represent and give "body" to the former (Giddens 2010).

The concept of Heritage is now extensive and covers different areas, but associated with the notion of Heritage there is always the idea of the need for its protection and enhancement. The Athens Charter (1931), proven to be decisive for the evolution of the concept of Heritage, leaving it to be exclusively linked to family and institutional structures, passing on the concept of Historical Heritage, which is intended for collective usufruct, to be fomented. Then, the Venice Charter of 1964 changed the notion of monument, which is no longer seen as an isolated architectural creation, extending this concept to urban or rural groups representing a particular civilization, a significant movement or historical event (Charter 1964).

From here on, the city is seen as a whole and a value to be preserved, within the line of thought of the "Convention Concerning the Protection of the world Cultural and Natural Heritage”, approved by UNESCO in 1972 (1972).

After that, there are many recommendations and conventions promulgated by UNESCO, in which the immaterial dimension assumes greater importance. Thus, in 1989, the "Recommendation on the Safeguarding of Traditional Culture and Folklore" (1989), in which UNESCO considers as well to safeguard cultural identity, as they are economically and politically determinant for contemporary culture. 
In 2001, the "Proclamation of Masterpieces of the Oral and Intangible Heritage of Humanity" (2001), was created by UNESCO, aiming to distinguish the most notable examples of cultural spaces, or forms of popular and traditional expression.

From the analysis of this problem we can conclude that there are two major groups of Heritage: the Natural and the Cultural. However, the Natural and the Cultural are inseparable and interconnect, giving rise to concepts such as cultural landscape, historic urban landscape, territories of cultural value and creative territories (Costa 2013).

With regard to Cultural Heritage, its division is made into two broad categories: "Material", within which we fit the Movable Heritage (works of art, objects, collections) and the Immovable Heritage (built: monuments, buildings and sets of buildings). The other major category of Cultural Heritage is designated as "Intangible", and according to the Convention for the Safeguarding for the Intangible Cultural Heritage, this is part of the cultural identity of peoples and communities and is constituted by the practices, representations, expressions, knowledge and skills-as well as the instruments, objects, artefacts and cultural spaces associated with them (2003).

\section{Cultural Routes and Wayfinding Systems}

Cultural Routes put in dialogue the different types of Heritage, showing the culture of the people and highlighting the spirit of the place.

The Spirit of the Place, according to the Québec Declaration (2008), consists of the tangible elements "(buildings, sites, landscapes, routes, objects) and intangibles elements (memories, narratives, written documents, rituals, festivals, traditional knowledge, values, textures, colours, smells, etc.), that is to say the physical and spiritual elements that give meaning, value, emotion and mystery to the place".

In turn, the cultural routes bring different types of heritage into dialogue and, according to the Charter on Cultural Routes (2008), they reflect the evolution of the concept of heritage and the role attributed to the environment and its significance at territorial scale, represent evolutionary, interactive and dynamic processes of human relations and cultural diversity. Cultural Routes are part of a natural and/or cultural context and contribute to their characterization and enrichment with new dimensions within the framework of an interactive process, and should be supported by tangible heritage elements which confirm the existence of intangible elements and together create meaning and significance.

Thus, these routes developed according to a procedural Design methodology based on wayfinding systems can promote user involvement, and create both cognitive and playful experiences that last in memory, contributing to the subjective well-being and happiness of the intervening parties.

To this end, the wayfinding systems, in a cultural context and of spatial ambulation, must enable multiple interactions in order to meet the needs and preferences of their users. In general, we can say that wayfinding systems result from the need 
to facilitate population the access to complex spaces and are, according to Berger (2009) and Gibson (2009), a Design intervention field, encompassing multiple study areas, whose objective is to facilitate the access and movement of people in a given space, as well as to enhance experiences.

A wayfinding system provides the necessary means to help people to orient themselves and feel at ease in their surroundings, enabling guided walking in a certain physical space (Gibson 2009).

However, it is considered that different approaches must be taken into account when designing a wayfinding system, and its purpose must be noted. We know, according to Costa (1989), that the needs determine the system, which must be created for each particular case.

Based on this principle, we consider that the approaches must be necessarily different, depending on whether it is a project aimed at a transport interface, or a project aimed at the knowledge and enjoyment of a space, such as cultural routes. The first, needs to be direct and accurate, providing information that allows easy access to a certain point, with a minimum of hesitation. In the second case, the wayfinding system, in addition to assisting in the route and access to a certain place, should enhance experiences involving the wayfinder, and promote different levels of knowledge, according to the interests and expectations of the user.

In the first case, the wayfinding system, due to its exclusively guiding function, makes the individual feel no discomfort. But, according to Costa (1989), these types of projects are not intended to leave marks on the memory of the individuals who carry them out. It is something that is forgotten immediately after reaching the goal.

In the case of a Wayfinding System developed for a cultural route, it should create memories, add knowledge and have a long-term impact on the individual.

Berger (2009) states that in the context of wayfinding systems, new spaces will be viable through the mixture of virtual reality, cyberspace and multiple intelligent materials, and that this will be a challenge for designers because they will need to include in their projects a set of transversal, even wider and improved capabilities.

According to Rosa (2012), wayfinding systems consist of a set of visual, physical, sensory and/or spatial elements that help the user to find a destination. The concept of wayfinding works better when the user has the capacity to conceive or mentally interpret a physical context and is able to place himself spatially in that representation. The idea of experience results from this connection between physical and sensory resources, to which we associate the knowledge of heritage and the protection of cultural diversity. In this way, through experience we can generate meaning and individual pleasure, providing subjective well-being. These steps, combined with the promotion and protection of cultural values, inscribe this type of projects in the so-called Positive Design.

Experience, knowledge and interaction are facilitated in contemporary society by the use of smartphones and tablets "The increasing ease with which individuals interact with mobile devices, the enhancement of their capabilities, as well as all the resources available online, open possibilities in the context of the creation of differentiated products for use in wayfinding systems" (Costa and Amaral 2020). 
Where we can use internet, GPS systems and augmented reality are now a possibility that greatly facilitates and enhances the users' experience, as well as allowing the search for multiple information based on geographic location. It will then be possible to access multiple information related to the history and memory of the different places that can integrate the itinerary. On the other hand, Augmented Reality can contribute to access information, and also provide a more playful approach to the realization of these routes.

Augmented Reality is an immersive experience that superimposes virtual 3D objects upon a user's direct view of the surrounding real environment, generating the illusion that those virtual objects exist in that space (Azuma 2017).

According to Costa and Amaral (2020), Augmented Reality provides inter-active experiences that are so valued today in our society. Augmented Reality creates layers that overlap the'real' world, allowing access to differentiated information, more indepth or more playful, depending on the goal to be achieved.

Azuma (2017) states that Augmented Reality AR will succeed in the consumer market sooner if it can establish new forms of media that users find compelling, enabling new forms of media and making meaningful connections between the virtual content and the surrounding real environment, generating experiences where the power comes from that connection and not solely from the virtual or solely from the real world.

Thus, we consider that multiple platforms combined in a Wayfinding project can enhance the experiences, which become pleasurable in the immediate and memorable in the long term, as long as the project is complete, integrate relevant information that allows the user to increase their knowledge, or provide recreational and game activities. However, there must be complete freedom for the user to decide how to carry out that itinerary, as well as the type and level of information he wants to obtain and, thus, Design can promote the experience and enjoyment of a certain place. Regarding the materials we considered here the use of digital media to be used using tablets or smartphones. However, the possibility of using analogue means (maps, flyers, routes and games) to satisfy different users cannot be excluded, providing them with access to a significant experience in the discovery of cultural heritage, achieved through a wayfinding system developed to carry out a Cultural Itinerary.

\section{Conclusions}

Given the growing importance of Happiness in contemporary society, a new area of Psychology designated as Positive comes into being. Positive Design emerges as a reflection of this concern and the care placed on the happiness of individuals, which is based on the principles of Positive Psychology. Results from the observation show that the culture of consumption of material goods has not promoted happiness and that new practices will have to be implemented in order to find solutions that make individuals happier. 
To this end, the authors analyzed in this paper, as well as in the manifesto of the Delf Institute of Positive Design, present a set of premises on which Positive Design must be based in order to achieve its greatest objective, that of promoting the well-being of individuals and contribute to their happiness.

On the other hand, in the face of a globalized world, local culture and cultural diversity are assets to be preserved, since culture integrates the most genuine features of each individual, group, community or country, presenting themselves through their heritage.

The Intangible Heritage: the stories, memories and traditions represented in the Material Heritage that gives it life and expression, must be placed in dialogue and made known through the development of Cultural Routes, revealed through Wayfinding Systems.

Wayfinding Systems, combined with multiple technological potentials, are considered to enhance experiences and promote different levels of knowledge, according to the interest and expectations of the user, constituting an opportunity to improve the lives of individuals by allowing an approximation to their roots in line with their values.

Immediate pleasure, considered decisive in the Positive Design process, is related to experience and derives from the pleasurable and positive moments that are achieved. In this case, the Wayfinding System using geo-referencing systems and Augmented Reality provide differentiated playful approaches that involve and call for the participation of the individual and contribute to a drift where discovery and play will result in dynamic experiences that enhance pleasure and fun, and positive emotions.

Signification is another of the determining elements in the development of Positive Design. Here, the focus is no longer the immediate, but relating to aspirations and individual cognition. In this approach, the individual's knowledge and values are unequivocally considered, as well as the possibility of access to different levels of knowledge.

In this way, the individual acts correctly in the protection of cultural specificities, in which he is inserted and with which he identifies. This is the parameter of virtue, considered a determining factor of Positive Design, recommended and defended by the authors addressed here.

We see, therefore, that the main values that legitimize Positive Design, pleasure, meaning and virtue, are foreseen in what we consider to be a wayfinding system for the realization of cultural routes. Although each of the three elements is not, or does not need to be present at the same level, none of the other elements is compromised. The level of presence of each of the elements depends on the individuals who take the journey and on their interests, since both platforms and the Wayfinding System allow freedom of choice, the adjustment of interests and motivations.

In this way, we consider that the development of Cultural Routes based on Wayfinding Systems which integrate different technologies and use multimedia support are means of promoting the subjective well-being of individuals. 


\section{References}

Azuma R (2017) Making augmented reality a reality. In: Proceedings of OSA imaging and applied optics congress (2017)

Berger C (2009) Wayfinding: designing and implementing graphic navigational systems. Rockport Publishers, Beverly

Berman D (2009) Do good - How designers can change the world. New Riders and AIGA Design Press, Berkeley, p 40

Charter V (1964) https://www.icomos.org/charters/venice_e.pdf

Charter of Cultural Routes, ICOMOS (2008) https://www.icomos.org/images/DOCUMENTS/Cha rters/culturalroutes_e.pdf

Convention Concerning the Protection of the world Cultural and Natural Heritage (1972) https:// whc.unesco.org/archive/convention-en.pdf

Convention for the Safeguarding for the Intangible Cultural Heritage (2003) http://portal.unesco. org/en/ev.php-URL_ID=17716\&URL_DO=DO_TOPIC\&URL_SECTION=201.html

Costa J (1989) Señalética: De la señalización al diseño de programas. CEAC, Barcelona

Costa ML (2013) Design para a Inteligibilidade e Fruição do Património Intangível - Itinerários Poéticos na Cidade de Lisboa. Tese de Doutoramento. Faculdade de Arquitetura da Universidade de Lisboa

Costa ML, Amaral I (2020) Communication design and space narratives. In: Raposo D, Neves J, Silva $\mathbf{J}$ (eds) Perspective on design (Springer series in design and innovation), vol 1. Springer, Cham, pp 103-113. https://doi.org/10.1007/978-3-030-32415-5_8

Cuche D (2003) A Noção de Cultura nas Ciências Sociais. Fim de Século Edições, Lisboa

Delf Institute of Positive Design. https://diopd.org

Desmet PMA, Pohlmeyer AE (2013) Positive design: an introduction to design for subjective well-being. Int J Des 7(3):5-19

Diener E, Biswas-Diener R (2008) Happiness: unlocking the mysteries of psychological wealth. Wiley, Hoboken, p 247

Gibson D (2009) The wayfinding handbook: Information design for public places. Princeton Architectural Press, New York

Giddens A (2010) Sociologia. Fundação Calouste Gulbenkian, Lisboa

ICOMOS: Athens Charter (1931). https://www.icomos.org/en/167-the-athens-charter-for-the-res toration-of-historic-monuments

Jordan PW (2000) Designing pleasurable products: an introduction to the new human factors. Taylor $\&$ Francis, London

Lynch K (1960) A Imagem da Cidade [The Image of the City]. Edições, Lisboa, p 70

Masterpieces of the Oral and Intangible Heritage of Humanity: Proclamations (2001, 2003, 2005) https://unesdoc.unesco.org/ark:/48223/pf0000147344

Myers DG, Diener E (2018) The scientific pursuit of happiness. Perspect Psychol Sci 13(2):218-225. https://doi.org/10.1177/1745691618765171

Norman DA (2004) Emotional design. Basic Books, New York

Press M, Cooper R (2009) El diseño como experiencia - El papel del diseño y los diseñadores en el siglo XXI". Editorial Gustavo Gili, Barcelona

Québec declaration on the Preservation of the Spirit of Place (2008) https://whc.unesco.org/upl oads/activities/documents/activity-646-2.pdf

Recommendation on the Safeguarding of Traditional Culture and Folklore (1989) http://portal.une sco.org/en/ev.php-URL_ID=13141\&URL_DO=DO_TOPIC\&URL_SECTION=201.html

Rosa C (2012) Informação Pictográfica - O universo dos pictogramas: Métodos e procedimentos de design para obtenção de coerência formal [Pictographic Information - The universe of pictograms: Design methods and procedures for obtaining formal coherence]. PhD Thesis. Faculdade de Arquitectura da Universidade Técnica de Lisboa, p 232

Saraiva AJ (2003) O que é a Cultura. Gradiva, Lisboa 
Schueller SM, Seligman MEP (2010) Differential pursuit of pleasure, engagement, and meaning: relationships to subjective and objective well-being. J Posit Psychol 5:253-263

Seligman MEP (2011) Flourish - a new understanding of happiness and well-being - and how to achieve them. Nicholas Brealey Publishing, London

Seligman MEP, Csikszentmihalyi M (2000) Positive psychology: an introduction. Am Psychol 55(1):5-14

Titiev M (1969) Introdução à Antropologia Cultural. Ed Fundação Calouste Gulbenkian, Lisboa 